\title{
Development of Organic and Sustainable Agricultural Education at the University of California, Davis: A Closer Look at Practice and Theory
}

\author{
Damian M. Parr ${ }^{1}$ and Mark Van Horn ${ }^{2}$
}

ADDITIONAL INDEX WORDS. experiential learning, interdisciplinary, curriculum, social constructivism, pedagogy

SuMMARY. In the mid-1970s, University of California, Davis, students concerned about the environmental and social consequences of modern agriculture were interested in exploring the practice and theory of "alternative" agriculture. These students organized to create new educational opportunities to address needs that were not being met by the existing curricula. These student-initiated opportunities emphasized interdisciplinary analyses of agriculture and field-based experiential learning; they included student-organized courses and the development of the Student Experimental Farm (SEF) as a site for student education, research, demonstration, and extension projects. Over the next three decades, the SEF developed diverse experiential educational projects, classroom and field-based courses focusing on sustainable and organic agriculture, and several departments and programs offered additional, related courses and curricula. In 2004, an interdisciplinary curriculum committee within the College of Agricultural and Environmental Sciences began to develop an undergraduate major in sustainable agriculture. A team of faculty and students within the committee conducted a broad stakeholder survey of agricultural practitioners, academics, students, and alumni to help inform decisions regarding what content, skills, and experiences to include in the curriculum. The survey findings reinforced the original curricular and pedagogical themes articulated and acted upon by students 30 years prior. The proposed curriculum is aimed at integrating disciplinary and interdisciplinary coursework in natural and social sciences, significant on- and off-campus experiential learning, and an emphasis on professional and interpersonal problem-solving and communication skills. Educational theory supports these diverse educational approaches and is useful in helping design courses and curricula in organic and sustainable agriculture.

$\mathrm{I}$ n the mid-1970s, University of California, Davis (UC Davis), students concerned about the environmental and social consequences of modern agriculture organized to develop new learning opportunities to explore "alternative" agriculture theories and practices. In 1975 the students worked with faculty to offer a new course, Seminar on Alternatives in Agriculture, which focused on topics such as small-scale organic farming, community gardening, food co-ops, the socio-economic consequences of agricultural research, and the impacts of agricultural policy on farming practices. In 1977, students began operating the

We thank Cary J. Trexler, Navina Khanna, Kristin Reynolds, and other members of the UC Davis Sustainability Curriculum Workgroup for their contributions.

${ }^{1}$ Agricultural Science Education, School of Education, University of California, Davis, CA 95616.

${ }^{2}$ Director, Plant Science Teaching Center and Student Farm, Department of Plant Sciences, Mail Stop 2 University of California, Davis, CA 95616.
Student Experimental Farm (SEF) as part of the newly formed Agricultural Alternatives Development Program (AADP) with the support from key faculty and administrators in the College of Agricultural and Environmental Sciences (CAES). In addition to granting access to 20 acres (8.1 ha) of land, the CAES dean agreed to student requests for funds to help support student-initiated research and education projects. From its inception, the SEF placed a strong emphasis on practical and experiential learning, student initiative and creativity, and the principles and practices of sustainable agriculture.

Within two years, the students in the AADP had developed a number of formal and informal educational offerings and launched several research and demonstration projects as well as a number of community action projects and events. These were in part publicized through the SEF Journalin 1979 (J. Kastler and A. Anderson, un- 
published) (Tables 1-2). Working with supportive faculty, students took the lead in offering new courses exploring a range of agronomic, environmental, social, economic, and ethical topics; course enrollments ranged from 17 to 75. Simultaneously, numerous research and education projects were initiated by students working with faculty mentors from a wide range of disciplines and departments. These projects emphasized multidisciplinary and interdisciplinary analyses of agriculture, field-based experiential learning and the integration of theory and practice. Topics included alternative methods of crop, livestock, and aquaculture production, pest management, cultivar development, and seed production, as well as cover cropping, composting, intercropping, and a national survey of alternative research and extension activities at land grant colleges. The students were also keenly interested in interacting with farmers, farm workers, and others in the greater community. They conducted a survey of local farmers, focusing on opportunities for collaboration between the farmers and the SEF, assisted a local farm worker cooperative, organized wellattended community workshops and conferences, and, by Summer 1978, 10 students had developed internships on area farms.

While the students' activities were supported and assisted by individual faculty members from various departments, it was the students themselves who led a variety of efforts to address needs that were not being met by the existing curricula. In general, subjects of interest to the students were, in fact, met with disinterest and even discouragement by many within the faculty. Organic farming, for example, was considered marginal at best by most faculty, whose attitudes reflected those of the majority within the agricultural community at the time. Similarly, faculty largely discounted students' pursuit of field-based practical learning, and the use of such methods had been increasingly excluded from the courses and curricula being offered. Nonetheless, there was sufficient determination by the students and moral, intellectual, and financial support from key faculty and administrators for the AADP and SEF to flourish. During the initial years, virtually all SEF financial resources were allocated to individual projects. Soon, however, the students and their

Table 1. List of Student Experimental Farm-sponsored university courses and community projects and events offered between 1977 and 1979. Numbers in parentheses represent university course numbers (J. Kastler and A. Anderson, unpublished).

University courses

Alternatives in agriculture seminar (Resource Science 198)

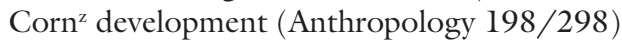

Ethical questions and planning criteria in projects (International Agricultural Development 198/298)

Organic agriculture: Fact and fantasy (Environmental Horticulture 198)

Community action projects and events

Farm worker cooperative resource coordination project

California rural apprenticeship program

Local farmer outreach survey

Women in agriculture conference

Draft horse workshop (co-sponsored by the Antique Mechanics)

Market garden field day/workshop (co-sponsored by the Experimental College)

${ }^{2}$ The following additional taxonomic information was not reported in the original source document: corn (Zea mays).

Table 2. List of projects initiated and conducted by students at the University of California, Davis, Student Experimental Farm between 1977 and 1979 (J. Kastler and A. Anderson, unpublished).

Mulching with clear tarps for yellow nutsedge ${ }^{z}$ control

Planned hedgerows for enhancing pest management

Honey bee ${ }^{z}$ hive demonstration

Corn improvement techniques for small farmers in developing countries

Simplified method for farmer produced seedless watermelon ${ }^{z}$ seed

Blue corn/amaranth ${ }^{z}$ study

Wheat $^{\mathrm{z}} /$ legume intercropping trials

Leguminous cover crops in almonds ${ }^{z}$

Rapeseed ${ }^{\mathrm{z}}$ cover crop study

Mosquito fern ${ }^{\mathrm{z}}$ applications in rice $^{\mathrm{z}}$ production

Small pond mixed species aquaculture

Overwintering of western mosquito fish ${ }^{z}$ in greenhouse aquaculture ponds

Solar straw bale greenhouse

Permanent beds for vegetable crops

Lamb $^{z}$ rearing project

Multipurpose windbreak demonstration

Windmill project

Compost production and evaluation projects

${ }^{2}$ The following additional taxonomic information was not reported in the original source document: yellow nutsedge (Cyperus esculentus), honey bee (Apis mellifera), watermelon (Citrullus lanatus), corn (Zea mays), amaranth (Amaranthus spp.), wheat (Triticum aestivum), almond (Prunus amygdalus), rape (Brassica napus), mosquito fern (Azolla spp.), rice (Oryza sativa), western mosquito fish (Gambusia affinis), lamb (Ovis aries).

faculty supporters realized that some resources and attention needed to be shifted toward the overall coordination and maintenance of the program and its facilities and equipment, and a paid farm manager was hired. Initially a half-time graduate student appointment, the farm manager position soon evolved into a full-time staff position.

During the 1980s, the SEF continued to develop as a site for student education, research, demonstration, and outreach/extension projects, with a growing emphasis on the theory and practice of sustainable agriculture. During this time, students involved in the SEF developed a number of ongoing educational projects that allowed students to gain practical experience and skills in a number of areas related to organic farming, ecological horticulture, and environmental education. These included the demonstration garden, the market garden, and the children's garden program. The demonstration garden (later renamed the ecological garden) was created as a place for students to learn about a wide range of cultivated plants and develop diverse skills used in ecological horticulture. In the larger-scale market garden, students grew organic vegetables for sale to an on-campus student-operated restaurant, and collected and composted the kitchen waste from the restaurant. 
Through the children's garden program, students provided grade school classes from the region with hands-on farm and garden tours focusing on agricultural and environmental topics. Over time, CAES allocated additional funds to support new part-time staff positions to coordinate these studentinitiated efforts. By the mid-1980s, there were three part-time staffand one full-time manager/director supported by CAES funds.

In addition to continuing to offer the Seminar on Alternatives in Agriculture course, in the mid-1980s the SEF began offering an intensive summer course in sustainable agriculture that each week combined several mornings of supervised field work with lectures, discussions, and field trips. In the 1990s, the SEF added two additional practical courses during the regular academic year; one focusing on organic crop production practices and another focusing on the methods and principles of garden-based education of children. During this period, a new major, called agricultural systems and environment, which included an area of specialization in sustainable production systems, was developed and a small number of course offerings began to explore issues related to agricultural sustainability. However, these efforts failed to build significant momentum and the initial enthusiasm for the major waned over time.

Since 2000 , there has been increasing student interest in sustainable agriculture as well as renewed student activism in this area. Student involvement in existing SEF activities and courses has increased and students have also created new projects, such as a biodiesel production and research project, and Project Compost. The latter is an effort funded by the Associated Students, which composts the kitchen waste from all campus food facilities at the SEF and includes a number of educational programs for students and the broader community. In 2003, a number of students from diverse programs formed Students for Sustainable Agriculture (SSA), an organization with interests, goals, and strategies that are very similar to those of the AADP of the 1970s. Members of the mostly graduate student SSA have taken an active role in a number of activities at the SEF and elsewhere on campus. They have helped organize the Seminar on Alternatives in Agricul- ture course, conducted a campus food system sustainability action research project, served on search committees for new faculty hires and other campus committees, and played a major role in ongoing efforts to develop a new undergraduate major in sustainable agriculture.

\section{Developing a sustainable agriculture major}

Outside the university, there have been significant changes in the agricultural community and the rest of society in the last decade. Sustainability issues have become increasingly prominent, and farmers and the agricultural community have responded in a variety of ways. One measure of this response is the increase in organic farming in both California and the U.S., with organic production growing $15 \%$ to $20 \%$ per year both statewide and nationally in the last decade (Dimitri and Greene, 2002; Klonsky et al., 2002).

The agricultural community is increasingly asking public institutions, including UC Davis, to play a more active role in the development and promotion of more sustainable agriculture systems and practices. Within this context, in 2002 the CAES dean appointed a committee of faculty and staff involved in sustainable agriculture education, research, and extension to develop a vision and plan for coordinating the college's existing sustainable agriculture activities and to recommend future activities in this area. The committee's first recommendation was for the college to establish an undergraduate major in sustainable agriculture, and the committee drafted a preliminary design for the major.

In Summer 2003, a public town hall meeting was held to publicize the committee's report and recommendations as well as to solicit feedback from internal and external stakeholders. At this meeting the recommendation for an undergraduate major enjoyed broad support, with stakeholders specifically advocating for the inclusion of social sciences, field-based experiential learning and a systems orientation within the curriculum. With this progress and stakeholder feedback, a Sustainable Curriculum Workgroup (SCW) committee of faculty and staff was appointed to develop a sustainable agriculture major that integrates natural and social sciences and to identify an appropriate administrative structure for the major.
Students successfully lobbied the CAES faculty for representation on the SCW committee.

During the SCW committee's initial deliberations, faculty and student members working in the field of education proposed a national survey to elicit the opinions and advice of stakeholders with knowledge and experience in sustainable agriculture or sustainable agriculture education. The goal of the study was to elicit input into the major from a broad range of stakeholders. Participants' input was gathered via an extensive web-based Delphi survey, a group process used to elicit, collate, and direct informed judgment toward consensus (Dillman, 2000). Four distinct groups were identified to participate in the study: academics from throughout the U.S. working in sustainable agriculture, currently enrolled U.S. undergraduates in majors focusing on sustainable agriculture and closely related fields, alumni of such programs, and agri-food system practitioners from within California. The survey took place from July through November 2004 and asked participants which content, skills, and experiences were important to include in a sustainable agriculture major.

The survey generated a wealth of detailed suggestions from each of the stakeholder groups (Trexler et al., 2006). The findings revealed a number of themes within each stakeholder group's suggestions, as well as strong similarities and agreement within themes occurring across groups (Khanna et al., 2005). Suggestions for content knowledge, experiences and skills that were consistent across all four stakeholder groups are summarized in Table 3.

\section{Proposed sustainable agriculture major design}

In addition to the survey, the curriculum committee utilized a number of sources of input in its deliberations and design of the curriculum. These included prior agricultural sustainability committee reports, comments from the 2003 town hall meeting, input from colleagues, and previously existing campus curricula. From these, the committee identified a number of guiding principles (Table 4) upon which it based the curriculum content and general design of the proposed major (SCW, unpublished). The major is currently in the proposal stage and 
under review by the faculty executive committee of the CAES. The major is expected to start in 2007 or soon thereafter. The college has begun hiring new tenure track faculty positions in both the natural and social sciences to teach in this major.

The guiding principles outlined in Table 4 directed the curriculum towards including disciplinary and interdisciplinary natural and social science course work, practical and experiential learning and skill building, and significant flexibility in upper division course selection. These features were intended to allow students to focus their studies in areas of greatest individual interest (see Fig. 1). While all students would take a broad range of prerequisite courses in both natural and social sciences and a common set of five interdisciplinary core courses, each student would choose one of two tracks to develop expertise in either the natural sciences or the social sciences. Within either track, the individual student would select first from courses that fulfill specific topical requirements, and then from a large menu of depth electives.

The proposed five core classes (SA $10,20,110,120$ and 160) include both lower division and upper division courses focusing first on agriculture and sustainability in general and increasingly on the specifics of social and ecological processes and systems.

The core sequence would culminate with a senior capstone course in which group projects allow teams of students from both tracks to bring their unique perspectives and skills to bear on specific case studies. Combined, the common preparatory, core and capstone courses would enable students to establish a shared knowledge base and social network.

Experiential learning and practical skills development would be emphasized throughout the major. Various experiential learning activities would be integrated into the core courses, with all students taking at least one on-campus applied agricultural production course. Among the mandatory on-campus production courses are existing courses in organic production methods, livestock management and field operation. Additionally, all students would complete one full-time, term-long, off-campus sustainable agriculture internship. A wide range of internships would be possible, including those on farms and

Table 3. List of suggestions that were consistent across the four Delphi survey stakeholder groups (Khanna et al., 2005).

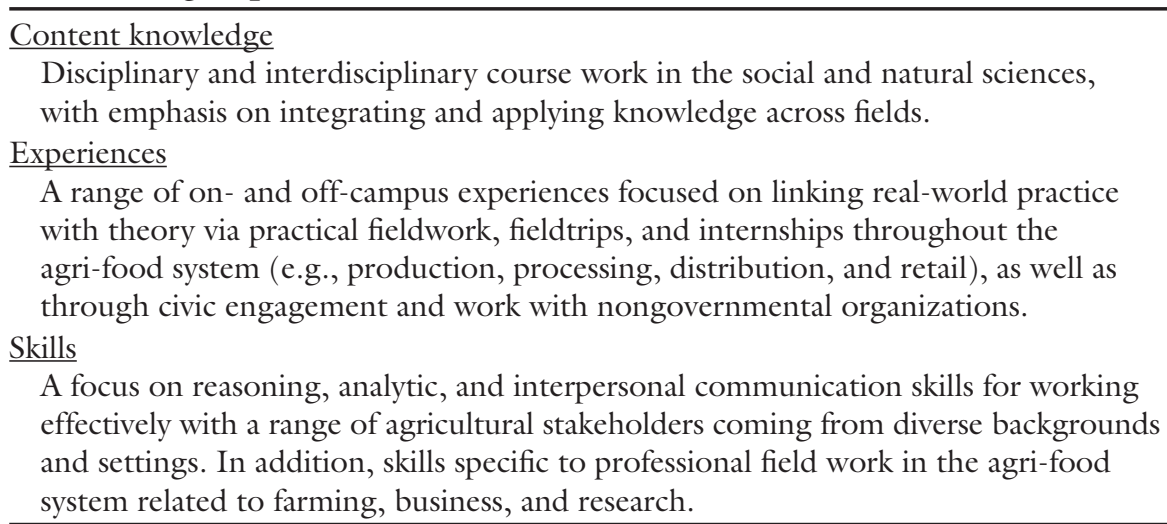

Table 4. The seven guiding principles of the proposed sustainable agriculture major at the University of California, Davis, as identified by the Sustainability Curriculum Workgroup (unpublished).

$\underline{\text { Interdisciplinarity }}$

Integrating natural and social science knowledge, skills, and understanding through interdisciplinary coursework is essential to comprehending the concept of sustainability.

Experiential learning

Students develop knowledge most effectively when learning is tied directly to purposeful activity, integrating theory and practice.

\section{Systems thinking}

Utilizing both reductionist and holistic methodologies is critical for understanding the complex and dynamic connections between agriculture, social institutions, and the environment.

Skill development

Working professionally in sustainable agriculture requires a broad range of practical and social skills, in addition to knowledge and theory.

Linking the real world with classroom

Agricultural interactions are contextual. Bring practitioner experts into the classroom, and provide students with real-world contexts and engagements.

Community building

Healthy rural and urban communities are essential to sustainable agriculture. It is likewise important to develop and maintain communities among the program's students, staff, and faculty.

Adaptive curriculum management

The innovative nature of the curriculum and major requires constant monitoring and adaptation via formal feedback processes involving students, alumni, staff, and faculty.

ranches and in food system related businesses, government agencies, and nonprofit organizations.

In order to support and guide a student in a highly interdisciplinary, experiential, and individualized curriculum, the committee proposed a specific advising structure and the creation of a staff academic advisor to help coordinate advising and on- and off-campus internships. In consultation with a faculty advisor, the staff academic advisor, and a peer advisor, each student would prepare an individualized course work plan that identifies the classes and internship experiences she or he would complete to fulfill the major. Such course plans would be part of the student's "portfolio." A portfolio would be developed over the course of the student's studies and include the student's academic plan, selections of work from courses, goals, objectives and accomplishments. The student would use the portfolio to actively strategize and critically reflect upon key progress from year to year.

The proposed curriculum design and advising structure were based on the committee's strongly held view that the proposed major must embrace an interdisciplinary and experiential 


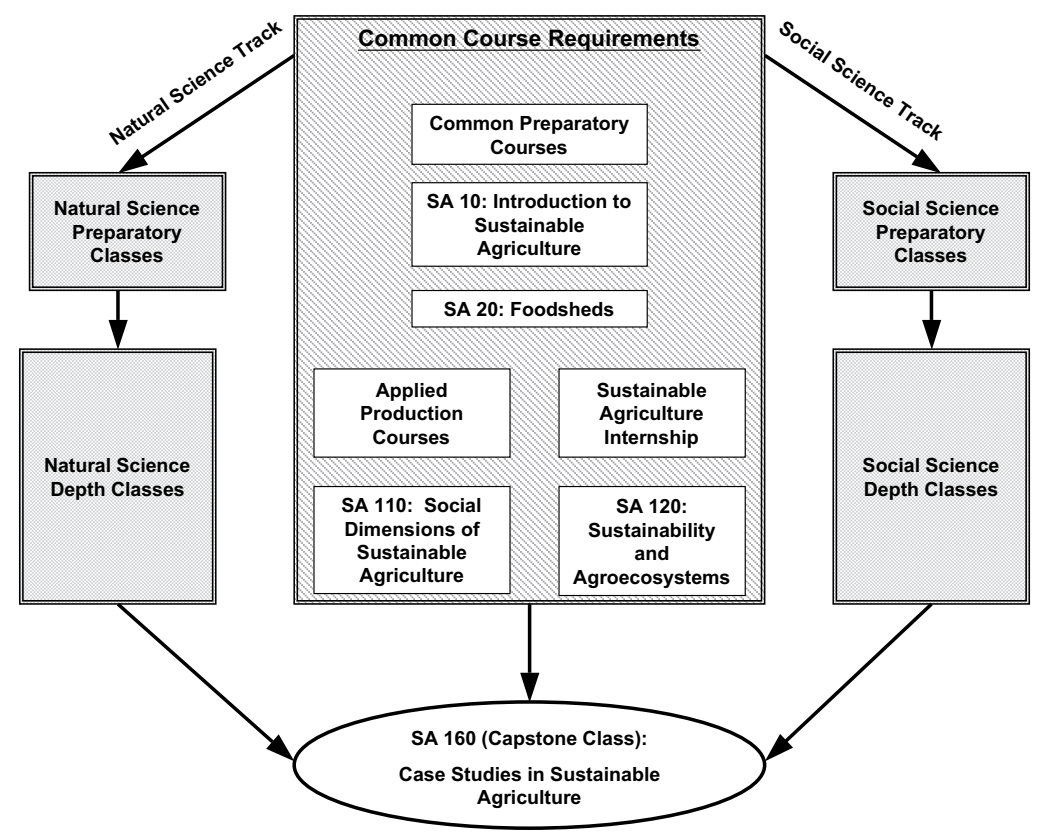

Fig. 1. Conceptual model of proposed University of California, Davis, sustainable agriculture major (Sustainability Curriculum Workgroup, unpublished).

approach, particularly in the delivery of its core courses. While recognizing that it represents a substantial break from university tradition, the committee proposed a non-departmentally based administrative model, believing it necessary to assure close and continuing cooperation among faculty from several different departments.

The structural dilemma of establishing a more integrative and interdisciplinary program in the context of a discipline-driven faculty and administration may be common at land grant universities (LGU). There have been a number of national calls to reform undergraduate education away from disciplinary and departmental isolation and towards interdisciplinary, experiential, and systems-based curricula. The National Research Council's Colleges of Agriculture at the Land Grant Universitiesreport (1996) claimed there was a need to remove historic disciplinary boundaries and encourage interdisciplinary research, teaching, and extension collaborations. The report called for the development of multidisciplinary and systems-based course materials and curricula. The authors also argued strongly that such curricula should require internships within diverse career settings found in the food and agricultural sciences.

Similarly, in Reinventing Undergraduate Education: A Blueprint for America's Research Universities, the Boyer Commission (1998) called for system-wide reformation of teaching and learning at research universities. The commission criticized the dominance of didactic teaching and passive learning, and overspecialization within disciplines through departmental hegemony. The report claimed the "concept of integrated education requires restructuring both the pedagogical and the integrative aspects of the research university experience" and proposed the adoption of inquiry-based interdisciplinary collaborative learning.

\section{Educational theory}

The National Research Council (1996) and Boyer Commission (1998) reports strongly suggest that effective undergraduate agricultural education must build on learning and teaching approaches that have become increasingly rare in curricula at LGUs. They thus reinforce the stakeholder recommendations received through the Delphi study (Khanna et al., 2005; Trexler et al., 2006) and town hall meeting, as well as nearly three decades of practice at the SEF. However, within an academic institution, it also is important to ask if these recommendations are supported by educational theory.

One theme common to the SEF, UC Davis town hall meetings, national LGU reports, and Delphi survey is the importance of experiential learning. According to Dewey (1938) and Kolb (1984), experiential learning is an approach to education that includes, but is not limited to, practical or hands-on activities. These authors argue for an approach to learning that cultivates not simply intellect or job readiness, but whole individuals, including the individuals' personal sensibilities and skills used in critically evaluating and engaging society. In other words, experiential learning focuses not only on students' cognitive development, but also on their affective development, that is, their thoughts and feelings about themselves and their work in the world. Experiential learning theory also suggests that students learn best when they are in action and engaging topics relevant to their personal interests and sense of purpose. Furthermore, for experiential learning to be fully realized, the students' purposeful actions or concrete experiences must be linked to an iterative cycle of reflective observation, abstract conceptualization, and experimentation (Katula and Threnhauser, 1999; Kolb, 1984). Through this experiential learning process, students create effective knowledge for use in the current situation as well as relevant future situations.

The educational basis of experiential learning is supported by a number of psychological and sociological theories referred to collectively as social constructivism. According to Piaget (1980) and Tobin and Tippins (1993), individuals gain knowledge of the world through an active process of constructing concepts and mental models, or schemas that give meaning and explanation to the world around them. Learning involves constantly, developing new knowledge by building upon, or revising and changing, previous conceptions (Driver et al., 1994). However, this knowledge development can only take place when newly introduced concepts are in some way relevant and within the cognitive reach of previously held conceptions, meanings, and explanations.

In addition to explaining learning processes internal to individuals, social constructivism argues that learning requires social engagement and communication through a shared language (Vygotski, 1978). The theory proposes that learners' schema develop through spoken interactions within social settings. Furthermore, social constructivism holds that learning happens most effectively within a "zone of proximal development," that is, when learners' schema are influenced by the relatively 
close, yet further developed, schema of others in their social setting (Lave and Wenger, 1991; Vygotski, 1978).

Those working in sustainable agriculture education at a few institutions have drawn heavily on progressive educational practice and theory, including experiential learning and social constructivist theories, in developing both undergraduate and graduate curricula. Interdisciplinary, experiential, and systems-based curricula have been implemented at Hawkesbury Agricultural College, New South Wales, Australia (Bawden, 1996, 1994, 1990), and the NOVA Agroecology program at the Norwegian University of Life Science in Aas (Francis et al., 2001; Lieblein et al., 2004). Both of these programs have focused more on students' learning processes and less on transmitting specialized bodies of scientific and technological knowledge. The curricula center on individual and social learning by building on students' interests and schema, and engaging student teams in active problem solving within real-world situations. In addition, the curricula support students learning how they learn. Students develop metacognition or conscious awareness of their education as a learning system by actively reflecting, abstractly conceptualizing, and experimenting with their individual and social learning processes (Bawden, 1990). This type of education focuses on students' lifelong learning capabilities and the attitudes necessary to facilitate projects with diverse stakeholders. The results are said to be an integrative understanding and set of skills that are effective in the development of sustainable agriculture.

\section{Conclusion}

For the past 30 years, UC Davis students have identified gaps in the educational programs being offered and formed and contributed to social organizations and efforts to fill those gaps. One of their accomplishments was the creation of the SEF, a program that has emphasized, among other things, opportunities for experiential learning. While it is unlikely that the students consulted educational theory in their endeavors, we can now reexamine their efforts in light of relevant theories, such as those cited above, and discover consistent agreement between these theories and the students' practices. Looking to the future, such theories are valuable because they help elucidate the learning process and, hence, identify what is important for effective curricula in sustainable agriculture. They help explain, for example, why experiential learning requires more than merely developing students' practical skills and knowledge. Experiential learning also necessitates building upon students' sense of purpose, current conceptions, and cycles of reflective observation, abstract conceptualization, and experimentation in real-world social contexts.

Ultimately, theory can help educators determine ways to more effectively integrate experiential learning into courses and curricula. As sustainable agriculture education continues to develop at UC Davis and elsewhere, curricula will be most successful when they build upon and explicitly incorporate the lessons of students' past and present efforts, stakeholders' suggestions, and theories that help us understand how students learn.

\section{Literature cited}

Bawden, R.J. 1990. Of agricultural systems and systems agriculture: Systems methodologies in agricultural education, p. 305-323. In: J.G.W. Jones and P.R. Street (eds.). Systems theory applied to agriculture and the food chain. Elsevier Appl. Sci., London.

Bawden, R.J. 1994. Creating learning systems: A metaphor for institutional reform for development, p. 258-263. In: I. Scoones and J. Thompson (eds.). Beyond farmer first. Intl. Technol. Publ., Warwickshire, U.K.

Bawden, R.J. 1996. A learning approach to sustainable agriculture and rural development: Reflections from Hawkesbury. Training for agricultural and rural development, 1995-1996. 3 Jan. 2006. <http://www. fao.org/sd/EXdirect/EXan0010.htm>.

Boyer Commission, 1998. Reinventing undergraduate education: A blueprint for America's research universities. Carnegie Foundation for the Advancement of Learning, Stony Brook, N.Y.

Dewey, J. 1938. Experience and education. Touchstone, New York.

Dillman, D.A. 2000. Mail and internet surveys: The tailored design method, 2 nd ed. Wiley, New York.

Dimitri, C. and C. Greene. 2002. Recent growth patterns in the U.S. organic foods market. U.S. Dept. Agr. Econ. Res. Serv. Agr. Info. Bul. AIB777.
Driver, R., H. Asoko, J. Leach, E. Mortimer, and P. Scott. 1994. Constructing scientific knowledge in the classroom. Educ. Res. 23:5-12.

Francis, C.A., G. Leiblein, J. Helenius, L. Salomonsson, H. Olsen, and J. Porter. 2001. Challenges in designing ecological agriculture education: A Nordic perspective on change. Amer. J. Alternative Agr. 16(2):89-95.

Katula, R. and E. Threnhauser. 1999. Experiential education in the undergraduate curriculum. Commun. Educ. 48:238-255.

Khanna, N., D. Parr, C.J. Trexler, and M. Van Horn. 2005. Informing the UC Davis curriculum development process: A Delphi study of sustainable agriculture stakeholders. 23 Mar. 2006. <http://education. ucdavis.edu/research/ag-sust-major/ UCD_SOE_Ag_Report.pdf>.

Klonsky, K., L. Tourte, R. Kozloff, and B. Shouse. 2002. A statistical picture of California's organic agriculture, 19951998. Univ. of California Agr. Issues Ctr., Davis

Kolb, D. 1984. Experiential learning. Prentice-Hall, Englewood Cliffs, N.J.

Lave, J. and E. Wenger. 1991. Situated learning, legitimate peripheral participation. Cambridge Univ. Press, Cambridge, U.K.

Lieblein, G., E. Ostergaard, and C. Francis. 2004. Becoming an agroecologist through action education. Intl. J. Agr. Sustainability $2(3): 1-7$.

National Research Council. 1996. Colleges of agriculture at the land grant universities: Public service and public policy. Committee on the future of the colleges of agriculture in the land grant university system, National Research Council. Natl. Acad. Press, Washington, D.C.

Piaget, J. 1980. The psychogenesis of knowledge and its epistemological significance, p. 23-34. In: M. Piattelli-Palmarini (ed.). Language and learning. Harvard Univ. Press, Cambridge, Mass.

Tobin, K. and Tippins, D., 1993. Constructivism as a referent for teaching and learning, p. 3-9. In: K. Tobin (ed.). The practice of constructivism in science education. Amer. Assn. Advancement Sci. Press, Washington, D.C.

Trexler, C.J., D. Parr, and N. Khanna. 2006. A Delphi study of agricultural practitioners' opinions: Necessary experiences for inclusion in an undergraduate sustainable agricultural major. J. Agr. Educ. 47(4).

Vygotsky, L.S. 1978. Mind in society: The development of higher psychological processes, p. 84-90. In: M. Cole (ed.). Harvard Univ. Press, Cambridge, Mass. 